\title{
TERRITÓRIO E MUDANÇA: CONTRIBUIÇÕES DA PROFESSORA JÚLIA ADÃO BERNARDES NO ESTUDO SOBRE O AGRONEGÓCIO NO BRASIL
}

\author{
TERRITORY AND CHANGE: PROFESSOR JÚLIA ADÃO BERNARDES' CONTRIBUTIONS TO A \\ STUDY ON AGRIBUSINESS IN BRAZIL
}

Catia Antonia da Silva ${ }^{\text {A }}$

\author{
${ }^{\text {A }}$ Universidade do Estado do Rio de Janeiro (UERJ), São Gonçalo, RJ, BRASIL
}

\begin{abstract}
Recebido em: 20/12/2021 | 04/01/2022 DOI: 10.12957/tamoios.2022.64322
Correspondência para: Catia Antonia da Silva (catia.antonia@gmail.com)
\end{abstract}

\begin{abstract}
Resumo
O presente artigo intenciona fazer a reflexão sobre o agir científico e o trabalho de formação de pesquisadores para o tema do agronegócio, efetuado pela professora Doutora em Geografia Júlia Adão Bernardes. A professora atua neste campo desde 1993, quando coordenou o estudo sobre a modernização agrícola no Brasil. Bastante versátil na sua relação entre ensino e pesquisa, ministra uma série de disciplinas que contribuem no entendimento sobre os conceitos de modernização, técnica, relações de poder e formas de reprodução das hegemonias, tendo como foco de investigação os setores: cadeia carne-grãos e sucroenergético. No presente artigo, a finalidade é divulgar o papel da pesquisadora e professora no fortalecimento da pesquisa cientifica geográfica sobre o tema do agronegócio no Brasil, contribuindo na elaboração de estratégias de organização de rede de estudos que fomentam produções acadêmicas, ementas de disciplinas dos cursos de geografias das universidades públicas nos estados de atuação dos impactos do agronegócio no Brasil e orientações de jovens pesquisadores. O exercício, efetuado de forma crítica e atualizada, acaba por contribuir na luta da visibilidade dos problemas da expansão da modernização agrícola na história dos lugares. As mazelas e impactos nas histórias dos lugares e das regiões são elementos que a Geografia tem assumido o compromisso de dar visibilidade, e Júlia Bernardes tem um papel protagonista importantíssimo na revelação desse modelo de modernização agrícola no território brasileiro.
\end{abstract}

Palavras-chave: agronegócio, modernização agrícola, território, técnica, biografia, investigação geográfica.

\begin{abstract}
This article reflects on scientific action and the work of training researchers on the theme of agribusiness carried out by Júlia Adão Bernardes, PhD in Geography. The professor has been working in this field since 1993, when she coordinated the study on agricultural modernization in Brazil. Quite versatile in its relationship between teaching and research, it teaches a series of disciplines that contribute to the understanding of the concepts of modernization, technique, power relations and forms of reproduction of hegemonies, focusing on the following sectors: beef chain- grains and sugar energy. In this article, the purpose is to publicize the role of the researcher and professor in strengthening geographic scientific research on the theme of agribusiness in Brazil, contributing to the development of strategies for organizing a network of studies that encourage academic production, discipline syllabuses from courses in geographies of public universities in the states where the impacts of agribusiness in Brazil are active and guidance provided by young researchers. The exercise carried out in a critical and updated way ends up contributing to the struggle for the visibility of the problems of the expansion of agricultural modernization in the history of places. The ailments and impacts on the histories of places and regions are elements that Geography has undertaken to give visibility to, and Júlia Bernardes has a very important protagonist role in revealing this model of agricultural modernization in Brazilian territory.
\end{abstract}

Keywords: agribusiness, agricultural modernization, territory, technique, biography, geographic investigation. 


\section{INTRODUÇÃO}

Todo conjunto verbal, se for grande e criativo, constitui um sistema de relações marcado pela complexidade e pela pluralidade de seus níveis. Uma atitude fecunda para com a língua exclui a palavra separada da voz, a palavra da pessoa. Em cada palavra há vozes, vozes que podem ser infinitamente longínquas, anônimas, quase despersonalizadas (a voz dos matizes lexicais, dos estilos, etc.), inapreensíveis, e vozes próximas que soam simultaneamente. Uma observação viva, competente, imparcial, sempre conserva, de qualquer posição, de qualquer ponto de vista, seu valor e sua importância. A parcialidade e a limitação de um ponto de vista (de um observador) são algo que sempre pode ser retificado, completado, transformado (reavaliado) mediante essa mesma observação realizada de um ponto de vista diferente. (BAKHTIN, Mikhail. Estética da criação verbal / [tradução feita a partir do francês por Maria Emsantina Galvão G. Pereira revisão da tradução Marina Appenzellerl. — 2' cd. —São Paulo Martins Fontes, 1997, p, 353.)

Júlia Adão Bernardes, é professora há mais de 40 anos no Departamento de Geografia da Universidade Federal do Rio de Janeiro, e atua no Programa de Pós-Graduação em Geografa. Com Pós-doutorado pela Universidad Nacional de San Martin (Argentina), no Programa de Estudios Rurales y Globalización (PERYG), em 2018, e doutorado concluído na Universidad de Barcelona (Geografa Humana), em 1993, tem desempenhado papel importante no fazer geográfico brasileiro e com reconhecimento importante na formação de recursos humanos, na produção de reflexões críticas sobre os impactos do Agronegócio no Brasil. A ela foi conferida a Bolsa Produtividade nível $1 \mathrm{C}$ do $\mathrm{CNPq}$ e o cargo de professora permanente da UFRJ, depois que se aposentou.

Em 1993, Júlia Adão Bernardes, em sua tese intitulada CAMBIOS TÉCNICOS Y REORGANIZACIÓN DEL ESPACIO EN LA REGIÓN AZUCARERA NORTE FLUMINENSE, BRASIL, na Universitat de Barcelona, UB, Espanha, analisa o papel do setor sucroenergético na região de Campos dos Goytacazes, município do Rio de Janeiro, verificando os investimentos públicos no projeto do Governo Federal, conhecido como PROÁLCOOL - Programa Nacional do Álcool, e a crise do setor no espaço fluminense, enquanto se ampliavam as áreas de produção de açúcar e de álcool no estado de São Paulo.

Em 1997 cria o Núcleo de Estudos Geoambientais (NUCLAMB), no âmbito do Departamento de Geografia da Universidade Federal do Rio de Janeiro, voltado para a investigação da temática técnica, trabalho, agricultura moderna e espaço, inserida na linha de pesquisa "Desenvolvimento, Ambiente e Território", do Programa de Pós-Graduação em Geografia, com vistas a tornar mais transparentes as implicações de ordem socioespacial das novas tecnologias e seus determinantes, no contexto do novo padrão de acumulação.

Júlia contribuiu e continua contribuindo na formação de graduados, mestres e doutores, que se tornaram professores universitários pelo país a fora, fator determinante para a 
compreensão da produção social e espacial, e ao mesmo tempo da construção discursiva das ideias e modelos de desenvolvimento, os quais, cada vez mais se pautam na redução do uso de mão de obra no campo e nas cidades vinculadas ao agronegócio.

Influenciada pelos estudos do professor Milton Santos sobre as mutações na urbanização brasileira, analisa a divisão territorial do trabalho entre campo e cidade, e identifica os impactos da modernização agrícola no Brasil, ao reconhecer que o interior dos estados estava crescendo economicamente mais do que as regiões metropolitanas. No caso do Sul e Centro-Oeste, esse crescimento se dava devido à reestruturação produtiva no país, com foco na modernização da agricultura. $\mathrm{O}$ cerrado, que historicamente era definido como bioma crescido em solo pobre de nutrientes, com o aprimoramento dos circuitos produtivos, das técnicas, dos cursos de agronomia, da implementação de tratores, insumos e matérias primas, foram algumas das referências tratadas por Milton Santos e que influenciaram sua obra.

A autora não queria fixar-se no velho espaço agrário brasileiro, já que o tema central era a mudança no campo, engendrada pela produção social e territorial do capitalismo no Brasil. Uma mudança fundamentada na lógica moderna da produção, distribuição e exportação/consumo, mas mantendo a lógica da concentração de terras e da produção latifundiária monocultora da soja, do milho, do algodão e da cana de açúcar. Nesse sentido, o setor da agricultura moderna vai se segmentando em produtos, com base na lógica de investimentos técnicos, adaptados à realidade do cerrado, avançando pelo Centro-Oeste através de grupos de empresários, alguns de vínculos familiares, que vão se especializando na governança corporativa da administração capitalista moderna.

Tal modernização da estrutura administrativa garante a especialização do trabalho, dos negócios e do espaço, tendo como fator primordial o apoio de investimentos públicos em estradas, em ciência e tecnologia, para garantir as inovações técnicas, a manipulação dos recursos naturais e a intensificação da produtividade. O tripé capital nacional, Estado e capital internacional atuam em conjunto, na medida em que essa modernização não seria somente para garantir o consumo nacional, mas principalmente a produção de commodities para inserção do país nas exportações e divisas internacionais.

O presente artigo tem como finalidade apresentar uma leitura da obra em construção de Júlia Adão Bernardes, ao longo de mais de 30 anos, visando contribuir na construção de um recorte biográfico interativo com a leitura geográfica do agronegócio no Brasil. A escolha de pesquisa da autora se confunde com a produção de uma literatura geográfica crítica sobre as escolhas de um modelo de modernização agrícola. Para Bakhtin (1997), voz e palavras escritas são simultâneas na organização do pensamento para a compreensão do mundo. Desse modo, trajetória de vida, produção textual e consciência de contextos, são exercícios da pesquisadora e professora Júlia, os quais produzem leituras que o presente artigo não tem a capacidade de expor, uma vez que os motivos, escolhas e trajetos de vida fazem parte da totalidade da vida, faces complexas visíveis e invisíveis; dizíveis e inexprimíveis. 
Do ponto de vista metodológico, o artigo foi elaborado a partir da leitura de artigos, das experiências compartilhadas em bancas de mestrado e doutorado, de participação de eventos e da imersão no currículo Lattes/CNPq. Com a finalidade de focar na compreensão das contribuições da autora no tema Agronegócio no Brasil, o artigo divide-se em duas partes: a primeira analisa a produção investigativa no setor de grãos (soja e milho), e a segunda está centrada no setor da política sucroenergética, ressaltando-se que a escolha textual não é linear temporalmente.

\section{RELAÇÕES COM OS RECORTES TEÓRICOS E METODOLÓGICOS NA PRODUÇÃO}

Bernardes elabora um campo de estudo que tem forte contribuição na compreensão do tempo presente. Processos estruturais e conjunturais revelam as articulações entre agentes privados e agentes nos espaços públicos, e como esse tripé vai fortalecer a expansão dos negócios no campo. A figura do fazendeiro dá lugar à do empresário, e as cidades dos notáveis, explica Milton Santos (1993), vão dar lugar às cidades do campo, na medida em que se estabelece cada vez mais forte relação entre a produção industrial de insumos, tratores, qualificação profissional e produção de técnicas de georreferenciamento para controle da produção agrícola. Assim, a expansão da modernização agrícola redefine, de certa forma, o papel da cidade no circuito espacial produtivo do agronegócio, e suas escalas de ação geográfica.

Portanto, as pesquisas de Júlia e seus orientandos contribuem para produzir uma literatura sobre o agronegócio no Brasil, com ênfase na região Centro-Oeste, revelando novas dependências do país aos modelos de fundo de financiamento e às articulações com agentes e agendas internacionais. A técnica, como conceito, torna-se central para esses estudos, integrando, enquanto categoria de análise para a compreensão dos processos de modernização, os circuitos espaciais (produção, circulação e distribuição) do agronegócio no Brasil.

Assim, quando se analisa a modernização do campo, remete-se à superação da ideia de fronteiras sociais e culturais entre campo e cidade, na medida em que o agronegócio é o processo de industrialização nos espaços agrários, cujos produtos têm como mercado as cidades e as exportações. Nesse contexto, a análise regional e a globalização tornam-se escalas territoriais fundamentais para a identificação das lógicas de produção e distribuição, assim como a compreensão da transformação dos lugares por onde avançam as áreas de cultivos da soja, milho, algodão, cana de açúcar e criação de animais da cadeia carne/grãos. 
Segundo Santos (1993), a expansão da modernização do campo, iniciada no Sul e Sudeste do Brasil, já na década de 1990 se expande para o Centro-Oeste do Brasil. Nos estudos de Bernardes, que se iniciam no Norte Fluminense, essa modernização vai em direção a Mato Grosso, e depois a outras regiões do Brasil, onde se expandem a soja, o milho, a pecuária e a cana de açúcar.

\title{
O FAZER CIENTÍfICO E ENCONTROS CONCEITUAIS E METODOLÓGICOS:
} AGRICULTURA, MODERNIZAÇÃO, TÉCNICA E EXPANSÃo REGIONAL

\begin{abstract}
Assim, trata-se de uma profunda mudança nos processos que construíram, gradualmente, a história das sociedades. Elos do novo meio (na forma de redes de equipamentos, linguagens, objetos) penetram na materialidade e no tecido social, articulando ou destruindo âmbitos anteriores da vida coletiva. A emergência deste novo meio ultrapassa a esfera do trabalho, ao mesmo tempo em que esta esfera se espraia para espaços, até agora, reservados, basicamente, à vida privada (como as novas formas de trabalho à domicílio e os computadores no espaço doméstico). $\mathrm{O}$ novo meio desobedece a âmbitos institucionalizados de organização da vida social, gerando mudanças - bastante radicais - em fronteiras, que constituíam referências, mais ou menos estáveis, das relações sociais e societais. (RIBEIRO, A. C. T. Traços da sociedade no meio técnico-científico e informacional apresentado no Encontro Internacional $O$ Mundo do Cidadão - Um Cidadão do Mundo, realizado em homenagem a Milton Santos pelo Departamento de Geografia da FFLCH-USP, entre 13 e 16 de outubro de 1996, Mesa Redonda "Globalização e Cidadania").
\end{abstract}

Júlia renova o tema da modernização na agricultura no Brasil, nos vários projetos de pesquisa que apresentaremos a seguir. O primeiro deles, após a defesa de doutorado, intitula-se "Técnica, trabalho e espaço: consolidação de um modelo" (1994-1996), que tinha como objetivo consolidar o modelo teórico tratado nos estudos da análise do sistema de modernização do circuito da cana-de-açúcar, tratado na tese de doutorado, a partir de novos setores produtivos, como a expansão da soja e da formação de complexos agroindustriais na região Centro-Oeste, com ênfase em Mato Grosso. O conceito de técnica é marcado com forte diálogo com a obra de Milton Santos (1996). O estudo proposto pela autora tem compromisso com a compreensão do setor econômico e com os efeitos espaciais das relações de poder político e econômico nas implicações humanas e da natureza.

$\mathrm{Na}$ década de 2000, a pesquisa se amplia para a análise mais aprofundada dos impactos das inovações tecnológicas na (re)organização territorial das atividades, dos recursos físicos e humanos do país, num momento em que Bernardes considera como um marco na transição paradigmática, no âmbito da criação de novas logísticas e da aplicação da biotecnologia à agricultura, de utilização de novo maquinário e insumos no processo produtivo. 
Considera e analisa a nova frente tecnológica e as consequências da modernização agrícola na divisão territorial e social do trabalho. A robotização, os incrementos em genética e a automação e uso de geoprocessamento de dados, vão ter impactos na produção do campo, com forte contribuição ao desemprego estrutural, com mão de obra cada vez mais especializada e, consequentemente, maior controle sobre a produtividade.

Nesse período, a compreensão do impacto da expansão da soja na modernização das cidades de Mato Grosso é importante para a análise da difusão das inovações que se iniciam no Paraná e no interior de São Paulo. Nas décadas anteriores, a fronteira da modernização avançara pelo Centro-Oeste, alterando as relações políticas locais e ampliando as classes médias produtivas na região.

Em 2007 a autora identifica um outro fenômeno que interage diretamente com seu tema: a produção do biodiesel em Mato Grosso, estendendo-se a pesquisa, posteriormente, a outros estados do Centro-Oeste e do Nordeste, como a Bahia e o Ceará. Analisou as repercussões da produção do biodiesel na reorganização territorial das atividades econômicas, dos recursos físicos e humanos, nas áreas de instalação das novas indústrias desse biocombustível, principalmente no maior polo em instalação do país, no município de Rondonópolis, em Mato Grosso, sob o comando da empresa Archer Daniels Midland (ADM), a gigante produtora de grãos nos Estados Unidos, que inaugurou, na época, a maior usina de biodiesel do mundo.

Segundo Bernardes, as consequências do projeto governamental sobre o biodiesel foram marcantes para a divisão social e territorial do trabalho, significando novas possibilidades de incorporação da pequena produção agrícola, de revitalização de espaços, especialmente em áreas de cerrado, implicando na criação de infraestruturas e de novas possibilidades produtivas. Desse modo, a pesquisadora faz um esforço para estudar as transformações econômicas promovidas nos espaços que ela denomina de fronteiriços, os quais exigem uma leitura geográfica, já que o conceito de espaço geográfico contribui para interpretar as estratégias modernizantes dos processos econômicos, sociais e ambientais do agronegócio no Brasil (BERNARDES, 2008).

Nesse período, alguns antigos orientandos de doutorado assumem o cargo de professor universitário, por meio de concurso público, o que demonstra a força teórico-conceitual e temática, articulada à formação de recursos humanos de pesquisadores e professores universitários no país.

Ainda, nessa década, Bernardes amplia os vínculos de pesquisa entre o Programa de Pós-Graduação em Geografia da UFMT e o da UFRJ. Além de ministrar cursos sobre geografia agrária e metodologia científica, propôs avaliar os efeitos do avanço da produção sojífera sobre o uso do solo e a dinâmica sócio ambiental na bacia do Teles Pires, no eixo da BR-163. Também analisa as transformações que estavam ocorrendo na BR-364, especialmente na área de Campo Novo do Parecis e Sapezal. Nesse período, a produção de soja nessa região apontava para a constituição de um complexo agroindustrial, surgindo novas 
articulações logísticas que redefiniam as interações espaciais desta região com os mercados de consumo globais, significando redefinição do espaço regional, sendo a logística direcionada no sentido de valorização do transporte inter-modal no rio Madeira, voltado para o escoamento das commodities produzidas na região noroeste de Mato Grosso.

Entre 2006 e 2008, por meio do projeto de pesquisa "Pré-Amazônia Mato-Grossense: a crise do agronegócio e os novos modelos produtivos”, Júlia identifica que o cenário otimista do mundo do agronegócio (1990 até 2005) começa a passar por uma séria crise, com acentuadas repercussões no setor produtivo. Dentre os fatores que contribuíram para essa crise estão: a taxa cambial desfavorável, dificuldades de ordem fiscal, problemas fitopatológicos e deficiências na logística, principalmente a falta de vias eficientes de escoamento e transportes, apesar dos vultuosos investimentos públicos no setor.

Nesse mesmo período, por meio de novo projeto de investigação, intitulado "Dinâmica das novas estruturas produtivas no cerrado norte/nordeste", Bernardes amplia a pesquisa para o bioma cerrado das regiões norte e nordeste. Segundo a autora, trata-se da emergência de novos padrões tecnológicos identificados no sul do Maranhão, sul do Piaú, nordeste do Tocantins e oeste baiano, onde o cultivo da soja se intensificou, impulsionado pela dinâmica da reprodução do capital, denominando essa nova região produtiva de Bamapito. Somente algum tempo depois, a mesma região recebeu oficialmente a denominação de Matopiba, como é conhecida atualmente. Segundo seus estudos e da equipe parceira, a inovação nessa área produziu nova organização da sociedade, a emergência de novas relações, eliminando atividades tradicionais para a implantação de atividades agrícolas modernas, emergindo a estruturação de complexos agroindustriais, estimulados pela proximidade das vias e portos de escoamento.

A análise da logística toma foco nesse projeto, onde a reflexão sobre distribuição e circulação de produtos, a infraestrutura das vias e dos transportes, apresenta uma das vantagens comparativas da região, segundo Bernardes. Os investimentos públicos e as intencionalidades dos empresários convergem para o estabelecimento de uma política viária que vem sendo direcionada no sentido da valorização do transporte intermodal.

Ainda no mesmo período, em outra frente de trabalho, Bernardes abre caminhos analíticos: trata-se da análise da expansão do agronegócio, por meio do projeto "Fronteiras em Mutação na Agricultura Moderna na BR-158 mato-grossense” (2006-2008). A finalidade era estudar a expansão da agricultura moderna, no que concerne à reorganização territorial das atividades econômicas, dos recursos físicos e humanos, particularmente em áreas de cerrado. A pesquisa contemplou o eixo da BR-158, devido à recente expansão da soja, voltada para exportação, em função da possibilidade de escoamento da produção em direção à ferrovia Carajás, rumo ao porto de Ponta da Madeira, no Maranhão. Bernardes aponta que a novidade da logística para estimular novos processos produtivos, por meio da criação de infraestrutura, teve repercussões de ordem econômica, política, social, ambiental e espacial, não somente a partir do escoamento da produção da BR-158 mato-grossense do Vale do Araguaia 
(BERNARDES; LOURENÇO, 2021), mas, também, das demais BRs que cortam o estado (BERNARDES, et all, 2021).

Neste movimento de expansão do agronegócio, Bernardes identifica processos semelhantes ocorridos em outros espaços, como rupturas dos ordenamentos anteriores, desagregações de vínculos sociais, desemprego, desconstruções, além de reconstruções de relações de poder político-econômicas entre grupos sociais tradicionais e os novos atores responsáveis pela expansão da agricultura moderna. Reconhece de forma mais densa as frações do capital (empresas nacionais e internacionais) articuladas nesse contexto, a dinâmica da espacialização do processo produtivo relacionado mais diretamente com a economia internacional, que resulta em intensas modificações locais e regionais. Afirma que as transformações promovidas nesses espaços exigem uma leitura geográfica, considerando que o conceito de espaço é de grande valia para interpretar as estratégias modernizantes dos processos econômicos.

Ao dar mais atenção à articulação das frações do capital nas escalas locais, regionais, nacionais e globais, Bernardes inova, também, trazendo a reflexão teórica sobre a categoria circuitos espaciais de produção e círculos de cooperação, no diálogo com Samuel Frederico e Ricardo Castillo. Entre 2007 e 2011 implementa o projeto "Circuitos espaciais de produção e círculos de cooperação: a integração da cadeia carne/grãos no cerrado mato-grossense”. Dessa forma, o campo de pesquisa avança para a compreensão do agronegócio na interação entre o setor de grãos (soja e milho) e o setor de carnes, que são impulsionados pela dinâmica de reprodução do capital.

No projeto "Os novos fronts da cadeia carne/grãos: o cerrado mato-grossense como modelo de referência", envolve os segmentos avícola, suinocultor e bovinocultor. A proposta está voltada para a compreensão dos processos que instituem os novos fronts, hoje representados por essas cadeias, as ações geradoras do sistema de fixos e fluxos e as formas espaciais resultantes (Santos, 1996), notadamente no que se refere à integração e à expansão de áreas urbanas antigas e recentes. As antigas áreas ganham novas funções e dinamismo, fazendo parte de redes de expansão da fronteira agrícola moderna em direção aos espaços naturais, às comunidades tradicionais e indígenas (BERNARDES; ARRUZZO, 2016). O caminho analítico de Bernardes envolvia o estabelecimento de conceitos e categorias, tais como os nexos entre ação, tempo e espaço. O intuito era compreender como as condições da região estavam sendo adaptadas às novas necessidades de inserção do país na economia globalizada.

Na década de 2010 a pesquisa de Bernardes, se aprofunda na compreensão do novo movimento do capital na cadeia carne/grãos na contemporaneidade. Passa a analisar as articulações entre empresas, setores e regiões, atenta aos fatores herdados, no movimento nacional e global, além do ritmo das mudanças e da expansão do agronegócio no Brasil. Aprofunda a análise dos impactos dos processos em andamento no que tange à capacidade competitiva de cada região. Verifica a incorporação de novas redes de poder no agronegócio, 
trabalhando conjuntamente com pesquisadores da rede de pesquisa de áreas agrícolas especializadas (REAGRI), possibilitando, dessa forma, maior apreensão das questões associadas às regiões especializadas do agronegócio, das novas relações campo/cidade e do aumento das desigualdades sociais.

Analisa também o tripé: universidades públicas, políticas públicas e intencionalidades empresariais no processo de modernização, na medida em que novas universidades foram criadas ao longo desses 30 anos de expansão do agronegócio, visando a implementação de cursos para formação e capacitação de corpo técnico, para aprimoramento dos setores produtivos e logísticos do agronegócio no Brasil. A escala de análise passa a alcançar as escalas de ação das empresas do agronegócio na sua inserção no espaço globalizado. Assim, o projeto intitulado "O recente processo de reorganização da cadeia carne/grãos: novas estratégias e escalas de ação" (2014-2018) traz a inovação metodológica de analisar a recente constituição das redes de poder econômico no setor carne/grãos do agronegócio brasileiro, identificar seus interesses, estratégias e práticas, com vistas à compreensão das transformações que vêm ocorrendo nas áreas de expansão desse setor na região Centro-Oeste, nas primeiras décadas do século XXI, incorporando na análise sua extensão à Argentina.

Bernardes verifica que as novas redes de poder promovem o rompimento de alianças tradicionais entre empresas e Estado, favorecendo o surgimento de novos arranjos institucionais, significando mudanças no poder de negociação, inviabilizando a relação de mão dupla, uma vez que o poder oligopolista das empresas gera concentração no processo produtivo, na propriedade e na esfera do trabalho, entre outros aspectos. Nesse contexto, a autora acentua que deve ser ressaltada a apreensão da importância do território no movimento do crescente processo de internacionalização do agronegócio e de uma nova divisão internacional do trabalho, e que é no âmbito do novo movimento do capital, onde emerge a criação de novos ambientes institucionais e de novos padrões tecnológicos, que busca compreender a cadeia carne/grãos enquanto rede de poder territorial, assim como os seus circuitos espaciais de produção e cooperação.

A manutenção metodológica entre a compreensão da permanência e da mudança é uma referência importante nos estudos de Bernardes, que tem atenção para as combinações com os fatores herdados no movimento mais amplo da modernização e do ritmo das mudanças. Da mesma forma, nas áreas de estudo, busca analisar os impactos dos processos em andamento no que tange à capacidade competitiva de cada uma. Bernardes acredita que a incorporação de uma perspectiva analítica centrada em redes de poder, possibilita a apreensão da questão das novas relações campo/cidade e do aumento das desigualdades sociais.

Do ponto de vista metodológico, o campo de investigação de Bernardes se amplia em densidade analítica, com a inserção do capital financeiro no setor. Bernardes identifica que está ocorrendo a ressignificação de formas de relação com o Estado e o território, suscitando uma abordagem com utilização de novos conceitos, como redes de poder, que possibilitam maior compreensão do movimento do capital na cadeia produtiva na contemporaneidade. 
Bernardes acredita que a incorporação de uma perspectiva analítica centrada no estudo do processo de regionalização como fato e como ferramenta (RIBEIRO, 2004) e em redes de poder (PAULILLO, 2000; MAZZALI, 2000) possibilita a apreensão das contradições (HARVEY, 2016) no que se refere à apropriação do território e ao aumento das desigualdades sociais.

\section{O RETORNO AOS ESTUDOS DO SETOR SUCROENERGÉTICO}

Em 2012, Julia Adão Bernardes organiza o I Seminário Nacional - Reestruturação do Setor Sucroenergético Brasileiro: novas e velhas espacialidades na UFRJ, que contou com pesquisadores e estudiosos sobre o tema do agronegócio no Brasil. Durante esse evento foi criada a rede de pesquisas REAGRI - Rede de Estudos sobre regiões agrícolas, visando articular reflexões, estudos e parcerias. Nessa reunião, constatou-se uma convergência de linhas e projetos de pesquisa, desenvolvidos nos laboratórios e núcleos de estudo em Geografia Econômica da UFRJ, UNICAMP, UECE, UNESP-Rio Claro, UFMT, UFRRJ, UFU, UFJF e UFG-Jataí, cuja preocupação fundamental era compreender a nova regionalização que emerge no território brasileiro a partir da especialização regional da agricultura capitalista e suas implicações sociais, econômicas e espaciais.

Os estudos sobre a política nacional de modernização agrícola no setor do açúcar e da bioenergia estruturam-se, no campo teórico e metodológico de Bernardes, por meio de projetos que retomam com profundidade a análise de 2010, o que pode ser constatado no projeto "O processo de expansão da produção de etanol no Brasil" (2010-2012) e "O processo de reestruturação do setor sucroenergético no estado do Rio de Janeiro: dilemas e desafios" (2011 -2013). Esses estudos tinham como objetivo averiguar as estratégias da produção de etanol nas diversas regiões do país, a exemplo de São Paulo, do Centro Oeste, do Nordeste brasileiro e Norte-Fluminense (RJ), bem como as repercussões desse processo na reorganização territorial nas atividades econômicas, dos recursos naturais e humanos, com consequências marcantes para a divisão social e territorial do trabalho, implicando na criação de infraestruturas e de novas possibilidades produtivas.

Nesse contexto, o processo de regionalização das estruturas produtivas do etanol a nível nacional, representaria a emergência de novas formas de politização da competição e da organização intra e inter empresas (BERNARDES, ARACRI, 2011; BERNARDES et al, 2013). Entre 2011 e 2016, os estudos no campo do etanol abrangeram duas escalas, como já foi citado: a escala do estado do Rio de Janeiro, analisando sua crise específica, e a nacional, que marcou a ascensão do setor bioenergético, fundamentado na incorporação de maquinários e insumos, que fez de São Paulo uma nova centralidade produtiva.

No projeto de investigação intitulado "Mudanças no paradigma sucroenergético: o movimento de reestruturação produtiva e as novas territorialidades" (2012-2016), acrescenta a 
análise sobre as grandes transformações que vêm ocorrendo na primeira década do século XXI, tornando o mundo mais unificado em função de novas condições científicas e técnicas e no contexto da chamada revolução ambiental; assim, a política energética e o uso dos recursos naturais passaram a constituir argumentos que se transformaram em fatores de competitividade, recebendo maior atenção por parte dos gestores públicos e privados.

Entre 2016 e 2019, Bernardes analisa as orientações conceituais e metodológicas sobre as escalas de ação, relações de poder e regiões competitivas, conforme já tinha estudado nas pesquisas da cadeia carne/grãos, visando aprofundar o papel do Estado nos arranjos institucionais e nas mudanças de negociação entre capital/trabalho/Estado. Amplia o estudo no Centro-Sul do país e fica atenta ao processo impulsionado pela dinâmica de reprodução do capital, que cada vez mais vem se intensificando, principalmente em São Paulo, no Triângulo Mineiro, Sul e Sudoeste Goiano, além de Paraná e Mato Grosso do Sul.

Abrindo novos caminhos e contribuições na formação de recursos humanos em Geografia, o campo reflexivo de Bernardes abona atenção aos impactos do agronegócio na escala do lugar, com referência às comunidades tradicionais indígenas, como descreve junto com Roberta Arruzzo (BERNARDES; ARRUZZO, 2016), na expansão do setor sucroalcooleiro em Mato Grosso, nas terras dos Guarani-Kaiowá. A orientação da dissertação de mestrado de Daniel Macedo Lopes Vasques Monteiro (MONTEIRO, 2017) e de Lívia Domiciano Cunha (CUNHA, 2020), constituem alguns dos exemplos de aprofundamento analítico dos impactos do agronegócio no lugar e no cotidiano das populações tradicionais na região de estudo.

\section{TEMPO BIOGRÁFICO E IMPORTÂNCIA HISTÓRICA: TECENDO ALGUMAS CONSIDERAÇÕES}

\footnotetext{
Chegamos assim à surpreendente aptidão de Goethe para ver o tempo no espaço. O que impressiona é o frescor e a vivacidade excepcional dessa visão do tempo (corrente, aliás, entre os escritores do século XVIII que pareciam ver o tempo pela primeira vez), que se explica em parte, é verdade, pelo fato de esta visão ser ainda relativamente simples e elementar, e por isso comportar um relevo mais sensível. Goethe tinha a vista aguda para todos os indícios e sinais do tempo na natureza: determinava muito depressa, a olho, a idade de uma árvore, conhecia o tempo de crescimento de diversas espécies de árvores, sabia ver as épocas e as idades. Tinha vista aguçadíssima para os indícios visíveis do tempo da vida humana (desde o tempo cotidiano de uma jornada do homem medido pelo sol e pela ordem das coisas até o tempo de uma vida humana inteira), das idades e das épocas da formação do homem. A substancialidade do tempo biográfico para Goethe, e a profundidade da visão desse tempo são comprovadas por suas próprias autobiografias - seus trabalhos biográficos que têm muito peso (Bakhtin, Mikhail. Estética da criação verbal / [tradução feita a partir do francês por Maria Emsantina Galvão G. Pereira revisão da tradução Marina Appenzellerl. — 2' cd. —São Paulo Martins Fontes, 1997, p, 249).
} 
Vale também ressaltar a importância histórica da produção de pesquisa e atividades de ensino da professora Júlia Adão Bernardes ao longo desses anos. Com muito rigor, produção de pesquisa científica de ponta no tema geográfico do agronegócio no Brasil, vem formando gerações de professores, pesquisadores, geógrafos e geógrafas de forma crítica. A formação se dá por meio das orientações de iniciação científica, monografias, dissertações, teses e trabalhos de pós-doutorado. Assim, as dezenas de orientandos de Júlia, hoje professores universitários, professores da rede pública, gestores e técnicos, compõem uma rede geracional importante que atualiza a metodologia da geografia do presente. É uma rede tão extensa, que vale a pena a escrita de outro artigo sobre essa produção científica. Essa rede fortalece o trabalho geográfico coletivo dos estudos sobre o agronegócio brasileiro, ministrando cursos, como o que proporcionou a elaboração deste número especial da Revista Tamoios, e desenvolvendo projetos de pesquisa no campo da Geografia Humana, mais especificamente no campo de análise das implicações espaciais do agronegócio. Assim, a obra em movimento e em construção, marcada pela vitalidade dos trabalhos de campo nas áreas expostas nos seus trabalhos de pesquisa e nas publicações, vêm contribuindo para revelar um país em que os processos de mudança tecnológica no campo não param de ocorrer, e que ingressa e consolida o país na lógica global do capitalismo contemporâneo, marcada pela produção de novas e velhas formas de desigualdades.

Os estudos sobre o agronegócio no Brasil constituem um desafio constante, sendo fundamental compreender as mutações estruturais e conjunturais, as reorganizações institucionais, que em pouco mais de 40 anos colocaram o agronegócio em evidência no Brasil; contudo esse mesmo agronegócio que engloba espaços rurais e urbanos, que através da técnica modifica as paisagens nacionais, também aprofunda a expulsão do campo e agudiza os conflitos ambientais, sociais e étnicos, mantendo-se a estrutura latifundiária como referência, somada ao incremento em tecnologia e ciência.

Do ponto de vista epistemológico, a relação entre ciência geográfica e biografia do ser é algo profundo de se pensar. Primeiro que não há ciência sem o trabalho intelectual. Num momento pandêmico e de muito negacionismo, compreender a obra de Júlia Bernardes nos remete ao aprendizado de Bakhtin (1997) quando reflete sobre o lugar da produção textual e da análise como uma relação situacional, ou seja, um contexto cujo esforço analítico se dá com o compromisso de falar ou de dar sentido a processos nem sempre compreensíveis, ou dar outro sentido, diferente do pensamento hegemônico, produzido pela simbiose entre produção moderna, publicidade e mídia. A riqueza do trabalho de Júlia Bernardes é de grande relevância para todos nós, que estudamos, diretamente ou não, os processos de mutação socioespaciais.

O fato de formar gerações com o compromisso com o pensamento crítico, faz de Júlia uma grande intelectual brasileira, cujos esforços são demonstrados nos eventos organizados e 
nas publicações realizadas, de forma compartilhada com professores de diversas universidades e com os seus orientandos.

\section{REFERÊNCIAS}

BAKHTIN, Mikhail. Estética da criação verbal / [tradução feita a partir do francês por Maria Emsantina Galvão G. Pereira revisão da tradução Marina Appenzellerl. — 2' cd. —São Paulo Martins Fontes, 1997;

BERNARDES, Júlia Adão; LOURENÇO, Taiana Ciscotto Martins. Estratégias territoriais da agricultura empresarial na fronteira agrícola moderna da BR-158 mato-Grossense. In: ROSSINI, Rosa Ester; MACHADO, Maria Rita Ivo de Melo; SAMPAIO, Mateus de Almeida Prado (Orgs.). Terra e trabalho: territorialidades e desigualdades. 1ed.São Paulo: FFLCH/USP, 2021, v. II, p. 284-311.

BERNARDES, Júlia Adão; MONTEIRO, Daniel Macedo Lopes Vasques; PEIXINHO, Dimas Moraes; MONTEIRO, Jorge Luiz Gomes; ARACRI, Luis Angelo dos Santos; ARRUZZO, Roberta Carvalho (Orgs.). O setor carne-grãos no Centro-Oeste: circuitos produtivos, dinâmicas territoriais e contradições. 1. ed. Rio de Janeiro: Lamparina, 2021. v. 1.320p .

BERNARDES, Júlia Adão; ARRUZZO, Roberta Carvalho. Expansão do setor sucroenergético e a história dos lugares: a questão territorial dos Guarani e Kaiowá em Mato Grosso do Sul. REVISTA DA ANPEGE, v. 12, p. 5-33, 2016.

BERNARDES, Júlia Adão; SILVA, Catia Antonia; ARRUZZO, Roberta Carvalho (Orgs.). Espaço e energia: mudanças no setor sucroenergético. 1. ed. Rio de Janeiro: Lamparina, 2013. 350 p.

BERNARDES, Júlia Adão; ARACRI, Luis Angelo dos Santos (Orgs.). Novas fronteiras do biodiesel na Amazônia: limites e desafios da incorporação da pequena produção agrícola. Rio de Janeiro: Arquimedes Edições, 2011. v. 1. 202p.

BERNARDES, Júlia Adão. I workshop: Novas Fronteiras do Biodíesel na Amazônia: limites e desafios da incorporação da pequena produção agrícola. 2008.

CUNHA, Lívia Domiciano. A fronteira em outra perspectiva: o avanço da fronteira agrícola moderna no Mato Grosso do Sul e a precarização das práticas espaciais Guarani e Kaiowa. 2017. Dissertação (Mestrado em Geografia) - Instituto de Geociências, Universidade Federal Fluminense, Niterói, 2017.

HARVEY, David. 17 contradições e o fim do capitalismo. São Paulo, Boitempo, 2016.

MAZZALI, Leonel. O processo recente de reorganização agroindustrial: do complexo à organização "em rede". São Paulo: Edunesp, 2000.

MONTEIRO, Daniel Macedo Lopes Vasques. Disputas territoriais em Mato Grosso do Sul: o tempo do direito dos Guarani-Kaiowá e Guarani-Ñandéva e as estratégias do agronegócio. 2017. Dissertação (Mestrado em Programa de Pós-Graduação em Geografia) - Instituto de Geociências, Universidade Federal do Rio de Janeiro, Rio de Janeiro, 2017.

PAULILLO, L. F. Redes de Poder e Territórios Produtivos. São Carlos: Rima: Editora da UFSCar, 2000 
RIBEIRO, Ana Clara Torres. Regionalização: Fato e Ferramenta. In: Limonad, Ester; Haesbaert, Rogério; Moreira, Ruy. (Orgs.). Brasil, Século XXI - por uma nova regionalização? Processos, escalas, agentes. Rio de Janeiro: Letra Capital Editora, 2004.

RIBEIRO, A. C. T. Traços da sociedade no meio técnico-científico e informacional apresentado no Encontro Internacional O Mundo do Cidadão - Um Cidadão do Mundo, realizado em homenagem a Milton Santos pelo Departamento de Geografia da FFLCH-USP, entre 13 e 16 de outubro de 1996 Mesa Redonda "Globalização e Cidadania

SANTOS, Milton. A natureza do espaço. São Paulo: Hucitec, 1996.

SANTOS, Milton. Urbanização Brasileira. São Paulo: HUCITEC, 1993.

\section{COMO CITAR ESTE TRABALHO}

SILVA, Catia Antonia. Território e mudança: contribuições da professora Júlia Adão Bernardes no estudo sobre o agronegócio no Brasil. Revista Tamoios, São Gonçalo, v. 18, n. 1, p. 7-20, 2022. Disponível em: https://doi.org/10.12957/tamoios.2022.64322. Acesso em: DD MMM. AAAA. 